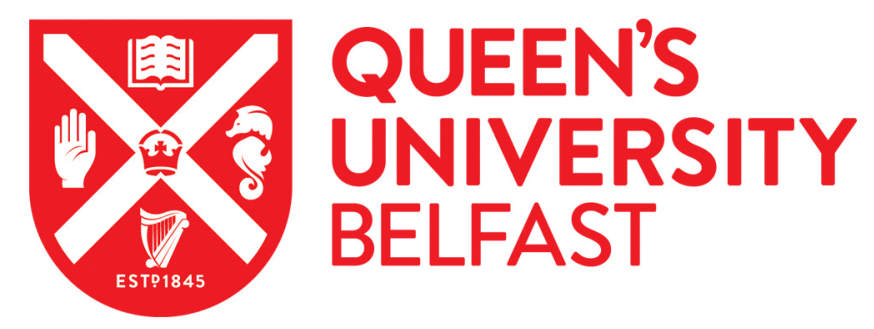

\title{
Microstructure of fibres pressure-spun from polyacrylonitrile-graphene oxide composite mixtures
}

Amir, A., Porwal, H., Mahalingam, S., Wu, X., Wu, T., Chen, B., Tabish, T. A., \& Edirisinghe, M. (2020).

Microstructure of fibres pressure-spun from polyacrylonitrile-graphene oxide composite mixtures. Composites

Science and Technology, 197, [108214]. https://doi.org/10.1016/j.compscitech.2020.108214

Published in:

Composites Science and Technology

Document Version:

Peer reviewed version

Queen's University Belfast - Research Portal:

Link to publication record in Queen's University Belfast Research Portal

\section{Publisher rights}

Copyright 2020 Elsevier.

This manuscript is distributed under a Creative Commons Attribution-NonCommercial-NoDerivs License

(https://creativecommons.org/licenses/by-nc-nd/4.0/), which permits distribution and reproduction for non-commercial purposes, provided the author and source are cited.

\section{General rights}

Copyright for the publications made accessible via the Queen's University Belfast Research Portal is retained by the author(s) and / or other copyright owners and it is a condition of accessing these publications that users recognise and abide by the legal requirements associated with these rights.

Take down policy

The Research Portal is Queen's institutional repository that provides access to Queen's research output. Every effort has been made to ensure that content in the Research Portal does not infringe any person's rights, or applicable UK laws. If you discover content in the Research Portal that you believe breaches copyright or violates any law, please contact openaccess@qub.ac.uk. 


\section{Journal Pre-proof}

Microstructure of fibres pressure-spun from polyacrylonitrile - graphene oxide composite mixtures

Amalina Amir, Harshit Porwal, Suntharavathanan Mahalingam, Xiaowen Wu, Tongfei Wu, Biqiong Chen, Tanveer A. Tabish, Mohan Edirisinghe

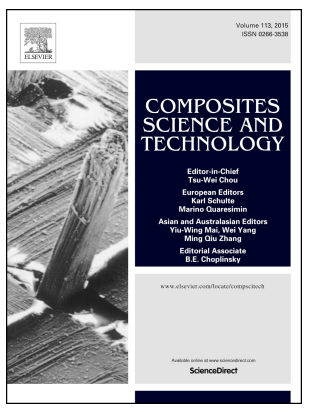

PII:

S0266-3538(19)32402-9

DOI:

https://doi.org/10.1016/j.compscitech.2020.108214

Reference: CSTE 108214

To appear in: Composites Science and Technology

Received Date: 10 September 2019

Revised Date: 20 April 2020

Accepted Date: 3 May 2020

Please cite this article as: Amir A, Porwal H, Mahalingam S, Wu X, Wu T, Chen B, Tabish TA, Edirisinghe $M$, Microstructure of fibres pressure-spun from polyacrylonitrile - graphene oxide composite mixtures, Composites Science and Technology (2020), doi: https://doi.org/10.1016/ j.compscitech.2020.108214.

This is a PDF file of an article that has undergone enhancements after acceptance, such as the addition of a cover page and metadata, and formatting for readability, but it is not yet the definitive version of record. This version will undergo additional copyediting, typesetting and review before it is published in its final form, but we are providing this version to give early visibility of the article. Please note that, during the production process, errors may be discovered which could affect the content, and all legal disclaimers that apply to the journal pertain.

(C) 2020 Published by Elsevier Ltd. 
Author statement

All authors acknowledge that the material presented in this manuscript has not been previously published, except in abstract form, nor is it simultaneously under consideration by any other journal. 


\title{
Microstructure of fibres pressure-spun from polyacrylonitrile - graphene
}

\author{
oxide composite mixtures
}

Amalina Amir ${ }^{\mathrm{a}, \mathrm{b}}$, Harshit Porwal ${ }^{\mathrm{c}}$, Suntharavathanan Mahalingam ${ }^{\mathrm{a}}$, Xiaowen $\mathrm{Wu}^{\mathrm{d}}$, Tongfei $\mathrm{Wu}^{\mathrm{e}}$, Biqiong Chen ${ }^{\mathrm{f}}$, Tanveer A. Tabish ${ }^{\mathrm{g}}$, Mohan Edirisinghe ${ }^{\mathrm{a}}$

${ }^{a}$ Department of Mechanical Engineering, University College London, Torrington Place, London WC1E 7JE, UK. ${ }^{b}$ Faculty of Mechanical Engineering, Universiti Teknologi MARA, 40450 Shah Alam, Selangor, Malaysia. 'School of Engineering and Materials Science, Queen Mary University of London, Mile End Road, London E1 4NS, UK. ${ }^{\mathrm{d}}$ School of Materials Sciences and Technology, China University of Geosciences Beijing (CUGB), 29\# Xueyuan Rd, Haidian District, 100083 Beijing, China. ${ }^{~}$ Department of Materials Science and Engineering, University of Sheffield, Mappin Street, Sheffield S1 3JD, UK. 'School of Mechanical and Aerospace Engineering, Queen's University Belfast, Stranmillis Road,

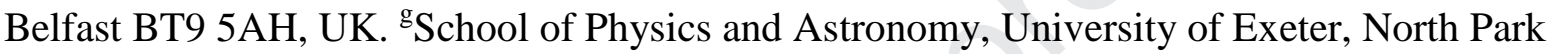
Road, Exeter, UK EX4 4QL, UK.

\begin{abstract}
Suspensions containing 8 and $10 \mathrm{wt} \%$ polyacrylonitrile (PAN) and 1, 2, 3, 5, 7 and $10 \mathrm{wt} \%$ graphene oxide (GO) were prepared using a special mixing routine and fibres were generated from these mixtures by pressurised gyration. The combination of pressure and gyration speed was effective in controlling the fibre morphology and fibre diameter which ranged from 1 $20 \mu \mathrm{m}$. Fibres were pyrolyzed to remove the polymer and only the $10 \mathrm{wt} \%$ PAN fibres survived. The microstructure of the pre- and post-pyrolysis products were characterised by scanning electron microscopy, both with and without focussed ion beam etching, Fouriertransformed infrared and Raman spectroscopies. Pyrolyzed fibre electrical conductivities were measured and only those containing 1 and $2 \mathrm{wt} \%$ GO were conductive.
\end{abstract}




\section{Introduction}

In recent years, there has been an increasing interest in graphene; as the specific surface area of graphene sheets is high owing to their single-layer morphology and two-dimensional nature. Graphene-based fibres have superior mechanical properties ${ }^{1-6}$. Reduced GO (rGO) fibres have recently been reported to be electrically and thermally conductive ${ }^{7}$, durable, flexible, and chemically resistant ${ }^{8}$. The potential applications of rGO fibres are in multifunctional textiles, wearable electronics, fuel cell, battery, sensor and filters ${ }^{9-14}$. GO made by oxidation of graphite, a cheap and abundant material compared to expensive singlelayer graphene. It is easy to process since it is dispersible in water (and other solvents), and it is used to make graphene.

Fabrication of graphene or GO fibres can be carried out by wet-spinning ${ }^{15}$, laser reduction ${ }^{16}$, coagulation $^{17-21}$ and pressurised gyration ${ }^{22,23}$. Most of these studies focused on the effects of wet-spinning, coagulation and reduction conditions. Uniform natural and synthetic polymer nanofibres could be mass-produced using simple one-step pressurised gyration more consistently, robustly and reliably at low cost compared to wet-spinning and electrospinning techniques. The successful dispersion of GO in suspension, on the performance of the obtained graphene fibres and application in energy storage devices, have been studied in detail $^{24}$. The focus of this paper is to use the pressurised gyration for making GO-loaded fibres and products derived from them, a topic that has not been studied in detail.

Graphene precursors such as graphite sulphate and polyacrylonitrile (PAN) have enabled studies of graphene fibres. A precursor is a compound that participates in a chemical reaction that produces another compound, in this case, graphene. PAN has been extensively studied 
for making carbon nanofibres because of its advantages of having a high carbon yield, compared with other polymers, and being relatively inexpensive ${ }^{8-10}$. Graphite sulphate was used as a precursor by Eigler ${ }^{25}$ however, the functionality was not proven with lower yields of graphene. Meanwhile, PAN, a form of acrylic fibre, is the predominant precursor material for the production of carbon fibres. The quality and composition of PAN precursors determine the ultimate performance of carbon fibres. A series of thermal treatments must be carried out to convert the PAN fibres to high tenacity carbon fibres, including thermal stabilization $\left(\sim 300{ }^{\circ} \mathrm{C}\right)$, carbonization $\left(\sim 1000{ }^{\circ} \mathrm{C}\right)$ and graphitization $\left(>2000{ }^{\circ} \mathrm{C}\right)^{26}$. PAN is desirable as a carbon precursor because of its higher melting point and greater carbon yield compared with pitch and rayon, the natural precursors. Some of the key challenges using natural precursors, which need further processing and purifying to form fibres, are that it is very expensive compared to PAN-based fibres ${ }^{27}$.

The use of pristine graphene in the development of graphene-based polymer composites is limited, owing to its high specific surface area and strong intermolecular interactions between graphene sheets which in turn limits the improvement in the properties of composites. Also, the electrical properties of graphene-polymer composites typically depend on electron percolation between independent filler particles. Hence, an excellent dispersion of graphene is important to produce a conductive polymer matrix.

Pressurised gyration, which involves high-speed rotation of a perforated pot containing a polymer solution, is a promising alternative method of spinning fibres and fibrous structures ${ }^{28,29}$. The high production rate (up to $6 \mathrm{kghr}^{-1}$ ), ease of processing and highly controlled fibre morphology are salient features of this technique ${ }^{28}$. In this work, the effects of process parameters on the properties of GO fibre such as fibre morphology and roughness, 
crystalline structure have been analysed in detail by scanning electron microscopy (SEM), Fourier-transform infrared spectroscopy (FTIR), Atomic force microscopy (AFM) and Raman spectroscopy (Raman). Also, PAN-GO composite fibres were prepared to investigate the effects of composition, speed and pressure on the structural morphology of the fibres. Some of the fibres were subjected to controlled pyrolysis after which electrical conductivity of the fibres was tested. The relationship between the processing parameters and the structural features of GO fibre are discussed in detail in this work.

\section{Experimental Details}

\subsection{Materials}

Polyacrylonitrile (average molecular weight 150,000 ), and N, N-dimethylformamide (DMF) was purchased from Sigma Aldrich (St. Louis, MO, USA) and used as received without further purification. The GO used in this study was synthesised according to a modified Hummer's method ${ }^{30}$ at the University of Sheffield, UK. The process is reproducible and GO particles were 2-3 $\mu \mathrm{m}$ diameter (Figure $\mathrm{S} 1(\mathrm{~d})$ ).

\subsection{Preparation of graphene oxide (GO) suspensions}

The preparation of GO suspensions and polymer solutions containing GO are detailed in

Supplementary Information S1. The detailed experimental procedures are also given in Supplementary Information S2. 


\subsection{Characterisation}

Details of characterisation of polymer solutions and the resulting products, in this case, composite fibres are given in Supplementary Information S3.

\section{Results and discussion}

Figure 1 shows that at the lowest rotational speed of $10 \mathrm{k} \mathrm{rpm}$ in the $8 \mathrm{wt} \%$ polymer composition, none of the compositions led to fibres, producing a polymeric spray instead. It is because the critical minimum rotation speed has not been exceeded, and it is too slow for a solution to move to the orifice and thus no polymer was accelerated to carry the GO particles and for the subsequent jetting to form fibres.

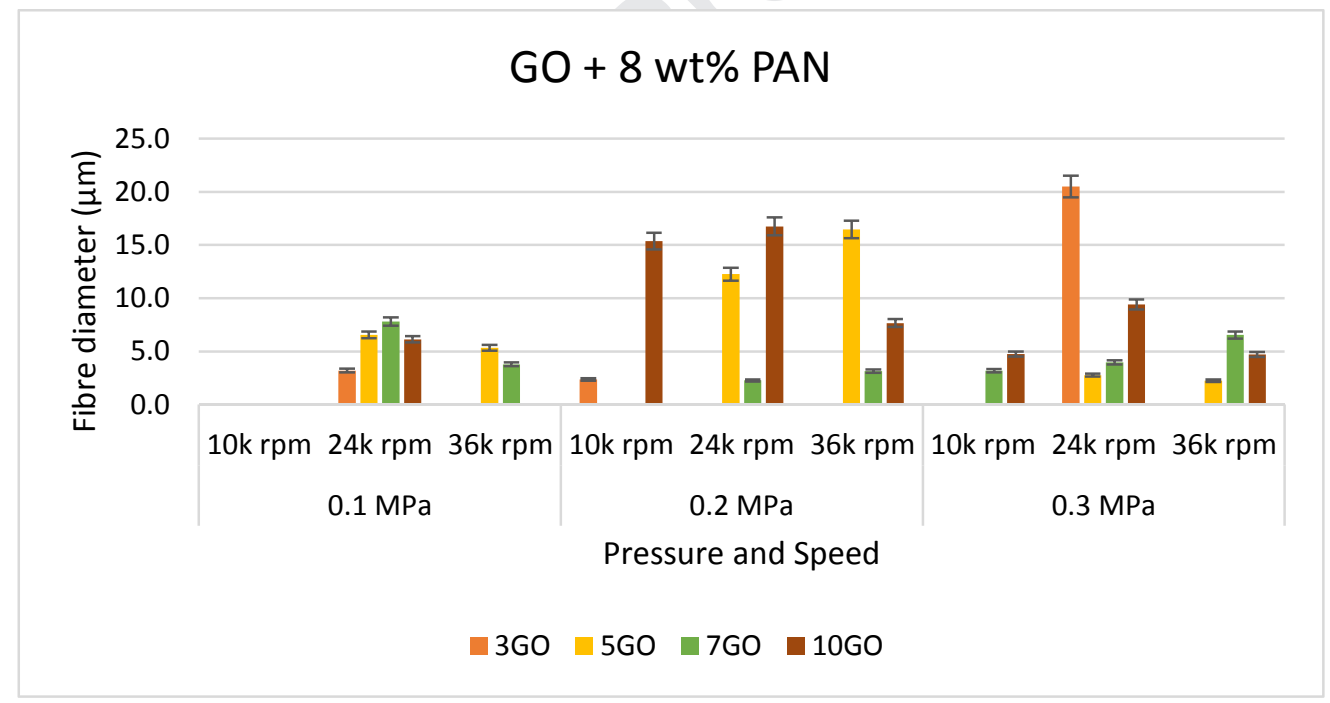

Figure 1 Diameter of fibres spun from 8 wt\% PAN at different speeds and pressures

On increasing the speed to $24 \mathrm{k} \mathrm{rpm}$, all of the solutions formed fibre composites as the centrifugal force exceeded the surface tension percolation threshold of the polymeric solutions, creating a polymer jet which subsequently leaves behind a bundle of fibres. These refer to fibre layer length (circumferential) that could be varied from 0.3-0.8 meters and 
each layer consists up to 100 fibres. At $3 \mathrm{wt} \% \mathrm{GO}$ fibre is the thinnest and most uniform in diameter. However, increasing the speed to $36 \mathrm{k}$ rpm, only $5 \mathrm{wt} \%$ and $7 \mathrm{wt} \%$ GO formed randomly orientated fibres. This is likely to be due to the sliding of GO sheets when the rotation speed was exceeded.

Increasing pressure to $0.2 \mathrm{MPa}$ with a rotational speed of $10 \mathrm{k}$ rpm allowed the preparation of smaller fibres, $3 \mathrm{wt} \%$ GO compared to $10 \mathrm{wt} \%$ has a much smaller diameter fibre (Figure 1) and is more uniform. With a higher percentage of GO, $7 \mathrm{wt} \%$ and $10 \mathrm{wt} \%$, the aggregation of GO might cause less sliding because steric hindrance at the surface of the GO sheets inhibits stacking, and stable dispersion inhibits agglomeration. This effect may cause a reduction in surface tension and increased viscosity and polymer entanglement. The $8 \mathrm{wt} \%$ PAN-based fibres had a mean diameter of $7.3 \mu \mathrm{m}$. The fibre diameter hence shows a gradual decrease in GO content, but the size distributions also broaden. Similar trends are seen with $10 \mathrm{wt} \%$ PAN which has a mean diameter of $6.2 \mu \mathrm{m}$.

The external driving force is the gravitational force when a polymer drop emerges from the orifices $^{28}$ because surface tension inclined along the liquid-air interface separates the drop from the surrounding air. Fibre formation from this process starts with a jet emerging from the orifice on the face of the vessel. The jet further stretches due to the centrifugal force and the pressure difference at the orifice. Finally, the evaporation of the solvent leads to thinning of the fibres. The reason for only jet formation instead of droplets in this surface instability is viscoelasticity of the polymer solution used ${ }^{28}$. Thus, most of the solutions did not produce fibres at $3 \mathrm{wt} \%$ GO $8 \mathrm{wt} \%$ PAN. 
Figure 2 shows the fibres formed when the speed is $24 \mathrm{k} \mathrm{rpm}$ and $36 \mathrm{k} \mathrm{rpm}$ at all concentrations and pressures. Composition of $10 \mathrm{wt} \%$ GO shows the highest fibre diameter considering all process variables, due to more GO particles in the fibres. For the $10 \mathrm{wt} \%$ PAN-GO fibres, at the lowest rotational speed of $10 \mathrm{k} \mathrm{rpm}$ and at $0.1 \mathrm{MPa}$ pressure, none of the compositions formed fibres, except $7 \mathrm{GO}$ and $10 \mathrm{GO}$. Increasing the speed to $24 \mathrm{k}$ rpm caused all the suspensions to form composite fibres. However, on increasing the speed to $36 \mathrm{k}$ rpm, all compositions formed fibres. At a pressure of $0.2 \mathrm{MPa}$ with a rotational speed of $10 \mathrm{k}$ rpm, 3 wt $\%$ GO didn't yield any fibre but all other compositions did. Increasing the rotating speeds to $24 \mathrm{k}$ and $36 \mathrm{k} \mathrm{rpm}$, caused fibres to form because they reach the stability of the polymer viscoelasticity.

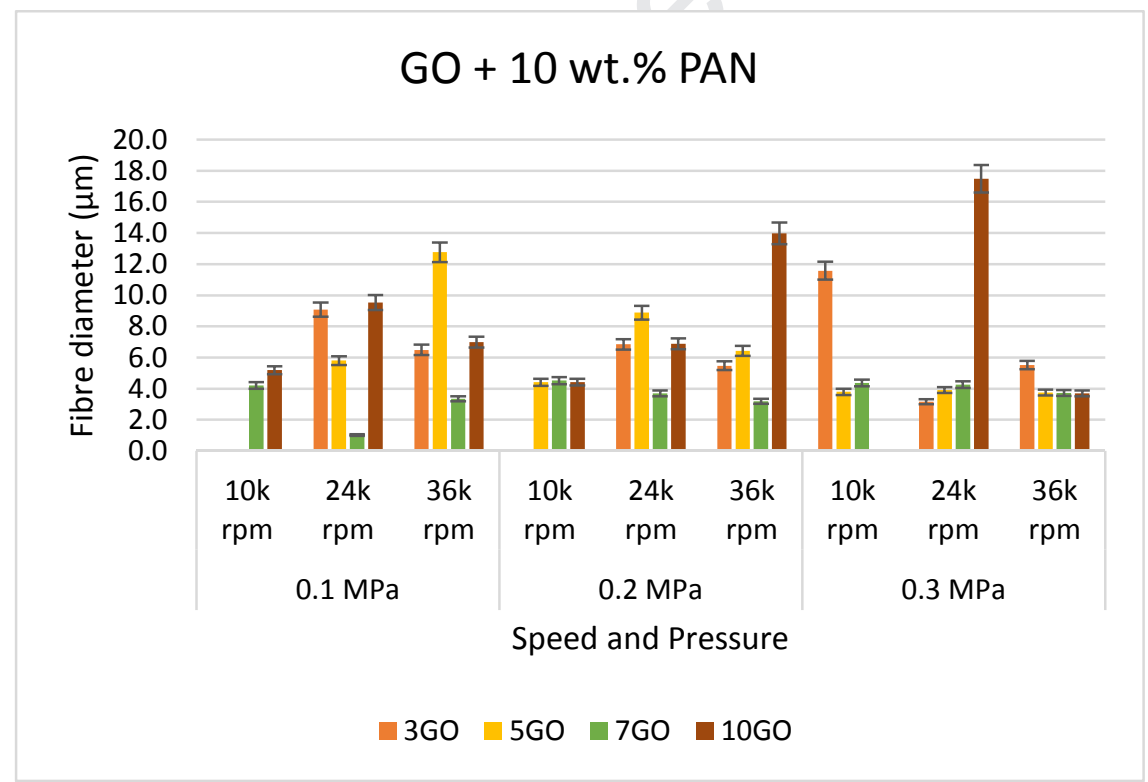

Figure 2 Diameter of fibres spun from 10 wt\% PAN at different speeds and pressures

Generally, fibre diameter is large for $24 \mathrm{k} \mathrm{rpm}$ compared to $36 \mathrm{k} \mathrm{rpm}$. At a pressure of 0.3 $\mathrm{MPa}$ with $10 \mathrm{k}$ rpm rotating speed, all the compositions produced fibres except 10GO. By increasing the rotating speeds to $24 \mathrm{k}$ and $36 \mathrm{k}$ rpm fibres were formed. Generally, fibre diameter didn't show any variation for $24 \mathrm{k}$ rpm and $36 \mathrm{k}$ rpm for all compositions, exclude 
10GO. It is well known that the centrifugal force applied to the polymer solution is the driving force for the jet formation and mostly affected by the rotating speed. It further influences the exit velocity of the jet, the jet's path to the collector and thus fibre diameter and the fibre morphology. The increase of rotational speed accelerates the polymer chain elongation, thus improving jet attenuation and the fibre diameter decreases.

However, the solution mass throughput from the nozzle not only depends on the rotating speed but is also governed by pressure difference at the orifice. On the other hand, rotating speed influences the airflow that acts outside of the spinneret and helps the evaporation of the solvent. Higher airflow accelerates solvent evaporation, which suppresses the elongation of the polymer jet resulting in thicker fibres. This may be the reason for the variation in the fibre diameters with various pressures in the process. Figure 3 shows the fibre diameter distribution for different polymer systems.
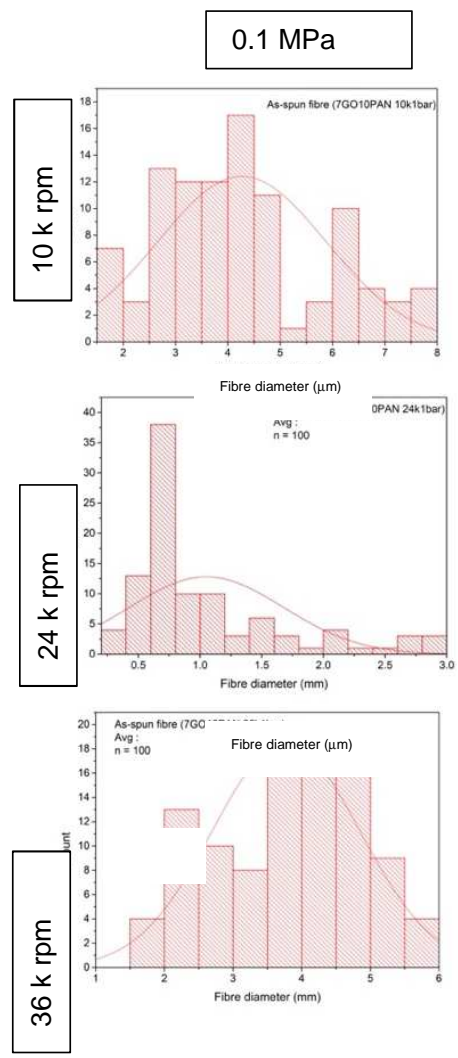

Fibre diameter ( $\mu \mathrm{m})$
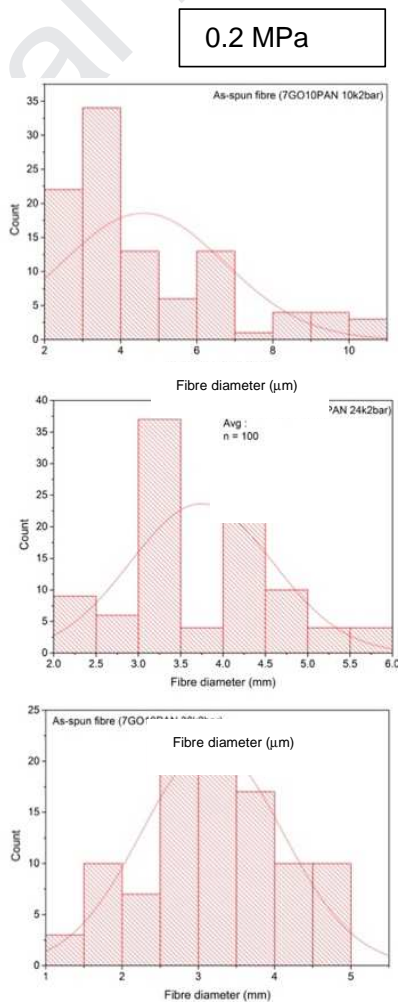

Fibre diameter $(\mu \mathrm{m})$
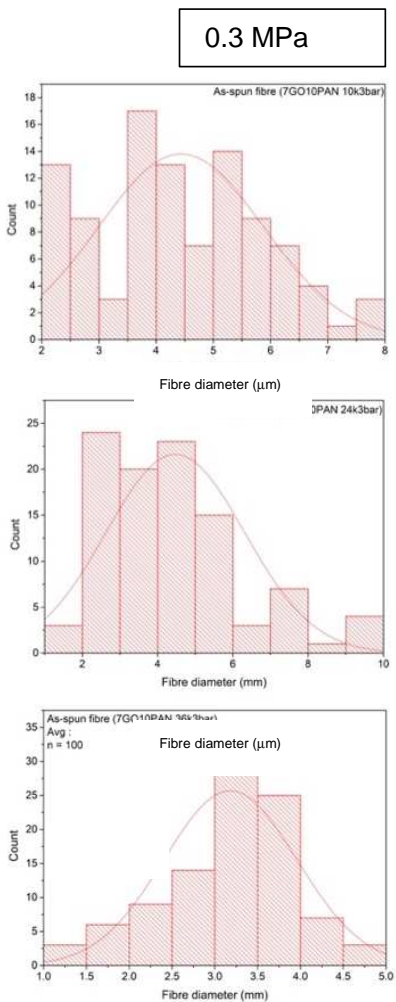
Figure 3 Diameter distribution of the 7GO 10PAN for different speeds and pressures.

In the $7 \mathrm{GO}$ - PAN polymer system, the mean diameter is $4.2 \pm 1.6 \mu \mathrm{m}$ at speed of $10 \mathrm{k} \mathrm{rpm}$ and $0.1 \mathrm{MPa}$. Increasing the speed to $24 \mathrm{k} \mathrm{rpm}$, mean diameter reduced to $1.0 \pm 0.62$ and increase to $3.4 \pm 0.64$ when the speed increased to $36 \mathrm{k}$ rpm. However, at a pressure of 0.2 $\mathrm{MPa}$ and 0.3 , mean diameter decreased when the speed is increased. At the speed of 10k rpm and pressure of $0.2 \mathrm{MPa}$, the mean diameter is $4.5 \pm 2.14$, then $3.7 \pm 0.85$ at $24 \mathrm{k} \mathrm{rpm}$ and reduced to $3.2 \pm 0.95$. Similarly, for the pressure of $0.3 \mathrm{MPa}$, at a speed of $10 \mathrm{k} \mathrm{rpm}$, the mean diameter is $4.4 \pm 1.45$ then $4.3 \pm 0.62$ and reduced to $3.7 \pm 0.84$ at the speed of $36 \mathrm{k}$ rpm.

SEM images of spun fibres using 3, 5, 7 and $10 \mathrm{wt} \%$ solutions and subjected to $10 \mathrm{k}-36 \mathrm{k}$ rpm and $1-3 \times 10^{5} \mathrm{~Pa}$ is shown in Figures 4 and 5. The mean fibre size ranged from $1-20$ $\mu \mathrm{m}$ for the $3-10 \mathrm{wt} \%$ solutions. At fixed $\left(1 \times 10^{5} \mathrm{~Pa}\right)$ pressure and $36 \mathrm{k} \mathrm{rpm}$ rotational speed a trend of increasing average fibre size is shown when the percentage of GO is increased.

This is attributed to the volume and mass of polymer solution that is being transferred across the orifice. Thicker polymer jets were formed at a higher polymer and GO concentration which, on the other hand, hinders the evaporation of the solution, causing a more significant transfer rate of the solution across the vessel orifices.

Fibre formation started at a lower concentration for $3 \mathrm{GO} 10 \mathrm{PAN}$ spun at $10 \mathrm{k}$ rpm at a pressure of $0.3 \mathrm{MPa}$ (Figure 4a). However, the speed was not enough to complete the process and jet out only fibres and polymeric lumps containing GO were found in the product. The increase in pressure from 0.1 to $0.3 \mathrm{MPa}$ is not sufficient to compensate for low speed. 

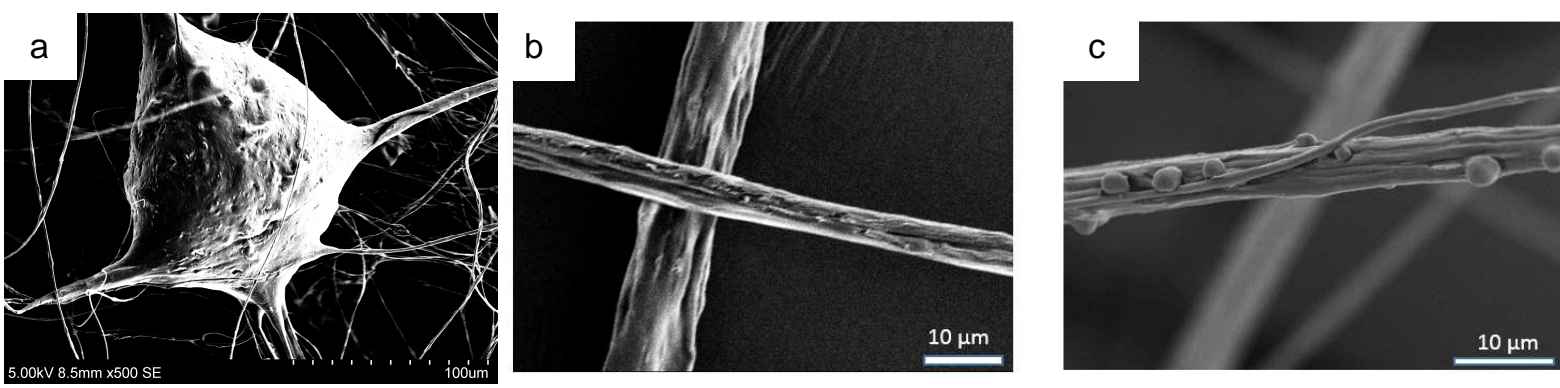

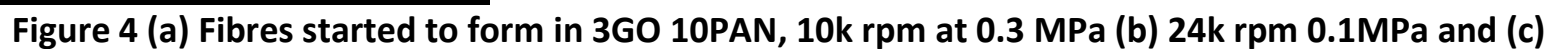
$24 \mathrm{k} 0.2 \mathrm{MPa}$

Figures 4 (b) and (c) shows that by increasing pressure, the PAN-GO solution is thinned and the disjoining pressure affects the capillary interactions between particles attached to the fibre surfaces. It appears that particles are protruding from a solution and that capillary rise of the liquid occurs along the surface of each particle ${ }^{31}$.

Figure 5 shows that at a speed of $36 \mathrm{k}$ rpm and pressure of $3 \times 10^{5} \mathrm{~Pa}$, in composition $3 \mathrm{GO}$ 10PAN fibres formed, in particular, Figure 5(b) shows that a graphene composite fibre knot can be stretched under tensile stress, leading to the high fracture elongation of the graphene fibre ${ }^{15}$
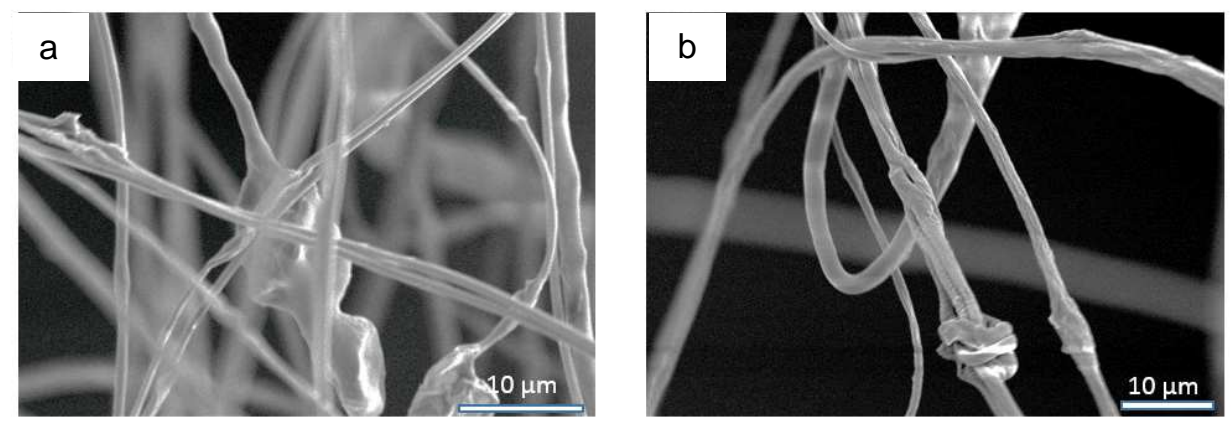

Figure 5 3GO 10PAN fibres obtained at 36k rpm with pressure at (a) $0.2 \mathrm{MPa}$ and b) $0.3 \mathrm{MPa}$

The influence of pressure applied during gyration in generating different fibre morphologies was studied by fixing the rotational speed at $36 \mathrm{k} \mathrm{rpm}$ and conducting experiments at $1 \times 10^{5}$, $2 \times 10^{5}$, and $3 \times 10^{5} \mathrm{~Pa}$ for $3-10$ wt $\%$ solutions. It is evident that, in general, a narrow 
diameter distribution of fibre diameter is achieved at higher working pressures (Figure 6).

At any fixed polymer concentration, by increasing the pressure, a trend of reduction in the fibre diameter was observed. This is due to the introduced gas stream which enhances the combined shearing force (consisting of centrifugal force and blowing) against the surface tension force in the elongational flow of polymer jets ${ }^{28}$. Therefore the diameters of the ejected polymer jets at the orifices of the vessel were reduced, which helps to promote thinner fibre formation. Solvent evaporation can be enhanced by blowing a hot air gun which affects the relative speed of airflow on the liquid-air interface in the polymer at the fibre surface, thus contributing to fibre formation. Reducing humidity to a range of $35-42 \% \mathrm{RH}$ also promotes fibre formation.

$0.1 \mathrm{MPa}$
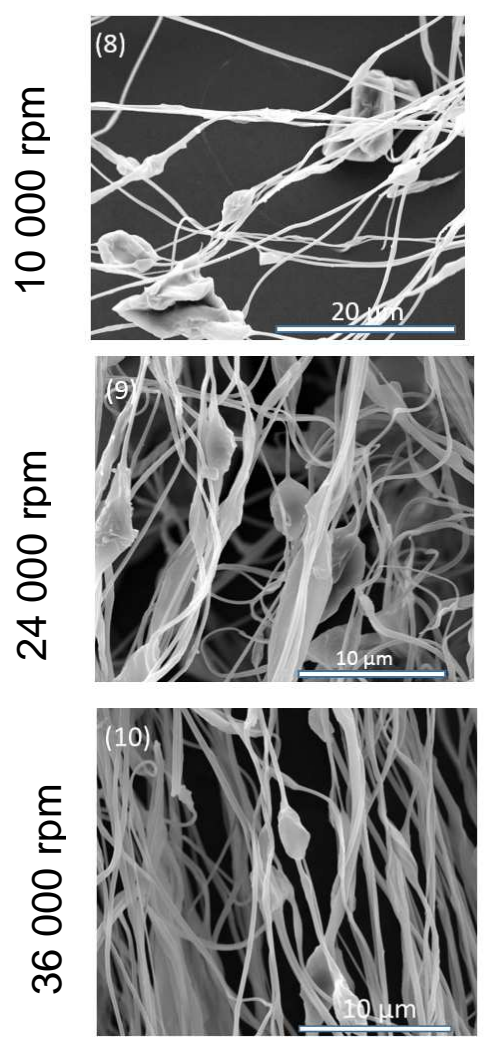

$0.2 \mathrm{MPa}$
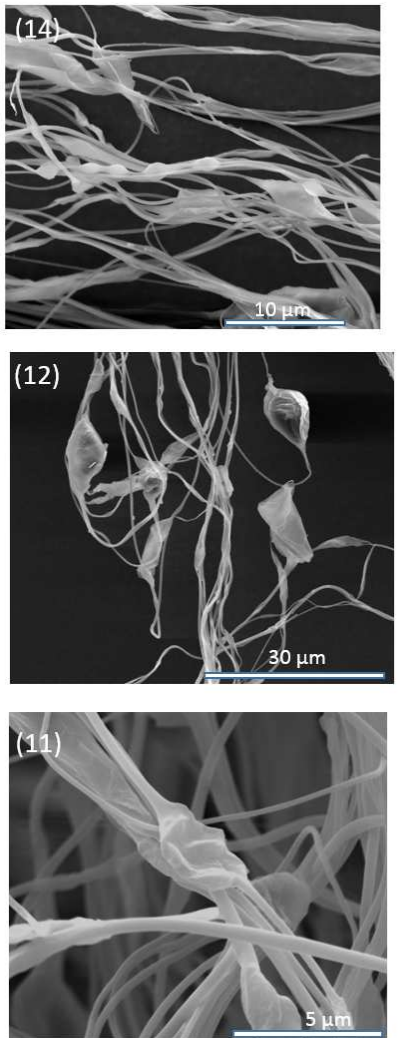

11
$0.3 \mathrm{MPa}$
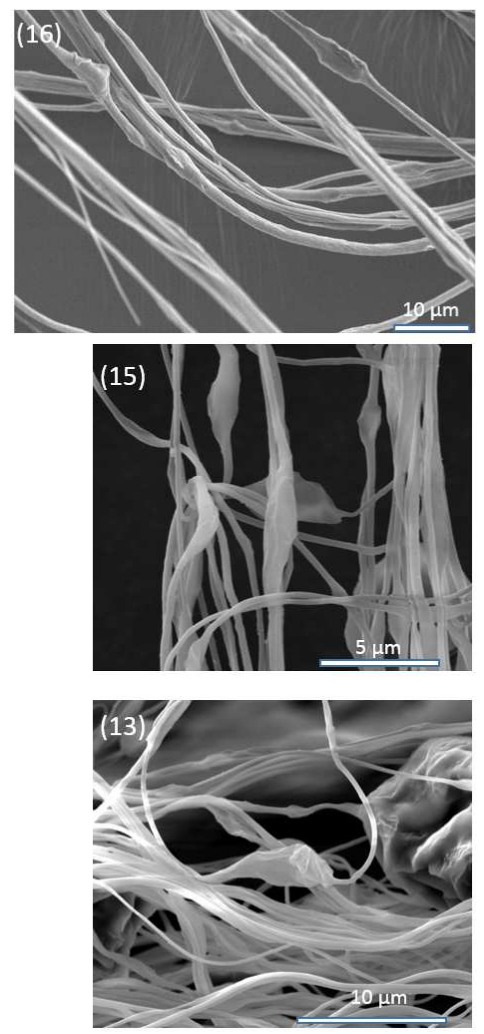
Figure 6 Scanning electron micrographs of7GO 10PAN fibres produced at different pressures and speeds

Initially, a jet emerges from the orifice on the face of the vessel. This jet further stretches due to the centrifugal force and the pressure difference at the orifice. Finally, the evaporation of the solvent leads to thinning of the fibers formed ${ }^{28}$. There was a strong relationship between the magnitude of pressure applied and the speed at which the solution escaped from the orifices, which led to improved fiber morphology. The morphology of fibers, homogeneity of fiber distribution, and production yield improved by increasing the spinning speed but was further enhanced by increasing the gas pressure ${ }^{32}$.

These results also indicate that the polymer concentration has a significant influence on the as-spun fibre morphology, that is, the increased polymer viscosity plays a role of stabilising polymer jets against the action of centrifugal force and dynamic solution blowing, hence promoting larger fibre diameter. When the polymer concentration is continuously increased, solvent evaporation is hindered. Hence it leads to the relatively long relaxation time/evaporation time during stretching. If the concentration of polymer is too low, only droplets or beads were formed or the creation of bead on string fibres was promoted. Higher molecular weight resulted in higher viscosity and a higher number of chain entanglements which means thicker fibres will be produced.

A minimum rotation speed that could result in enough viscous solution response enables the generation of nanofibres at lower polymer concentrations. On the whole, increasing rotational speed accelerates stretching of polymer jets, this decreases the diameters of the polymer jets at the orifices of the vessel, and thinner fibres are obtained. It is seen that, overall, narrower size distribution is obtained at a higher rotational speed. It is noteworthy that at $10 \mathrm{k} \mathrm{rpm}$, not 
all the solutions are spinnable using a typical pressurised gyration method at a pressure of $1 \times$ $10^{5}$ Pa using $8 \mathrm{wt} \%$ PAN.

It is a significant challenge to directly assemble 2D GO sheets into $1 \mathrm{D}$ fibres without any polymer or surfactant, due to the lack of scalable assembly methods ${ }^{33}$, the size and irregular shape of chemically derived graphenes and the movable layer-by-layer stacking of graphenes $^{34}$. Therefore, in order to integrate the remarkable properties of individual graphene sheets or its derivatives into advanced, macroscopic, and functional structures for practical applications, an effective assembly strategy in a well-controlled way has to be developed ${ }^{19}$. And this work paves the way for that.

\subsection{Fibre chemistry}

Polymer compatibility is a crucial factor in determining the stability of fibres. If the GO is not compatible with PAN polymer, then a solid phase separation will be observed. Secondary interactions such as hydrogen bonding, hydrophobic reactions, and electrostatic forces can increase the compatibility in the fibres ${ }^{35}$. FTIR spectroscopy has been used to reveal the bonding profile of composite, GO and PAN. FTIR spectra of GO, PAN and PAN-GO are represented in Figure 7. The FTIR spectrum of GO shows characteristic bands at $3500 \mathrm{~cm}^{-1}$ (C-H stress) and $1500 \mathrm{~cm}^{-1}$ ( $\mathrm{C}=\mathrm{O}$ stress), while the spectrum of GO-PAN contains peaks at $2448 \mathrm{~cm}^{-1}(\mathrm{~N}-\mathrm{H}$ stretching, aromatic and aliphatic C-H stretching). The frequency of the physical mixture is a composite of the pure polymer, containing all the characteristic bands of GO-PAN. This indicates that the interactions between GO and the polymer are weak when they are mixed physically. 


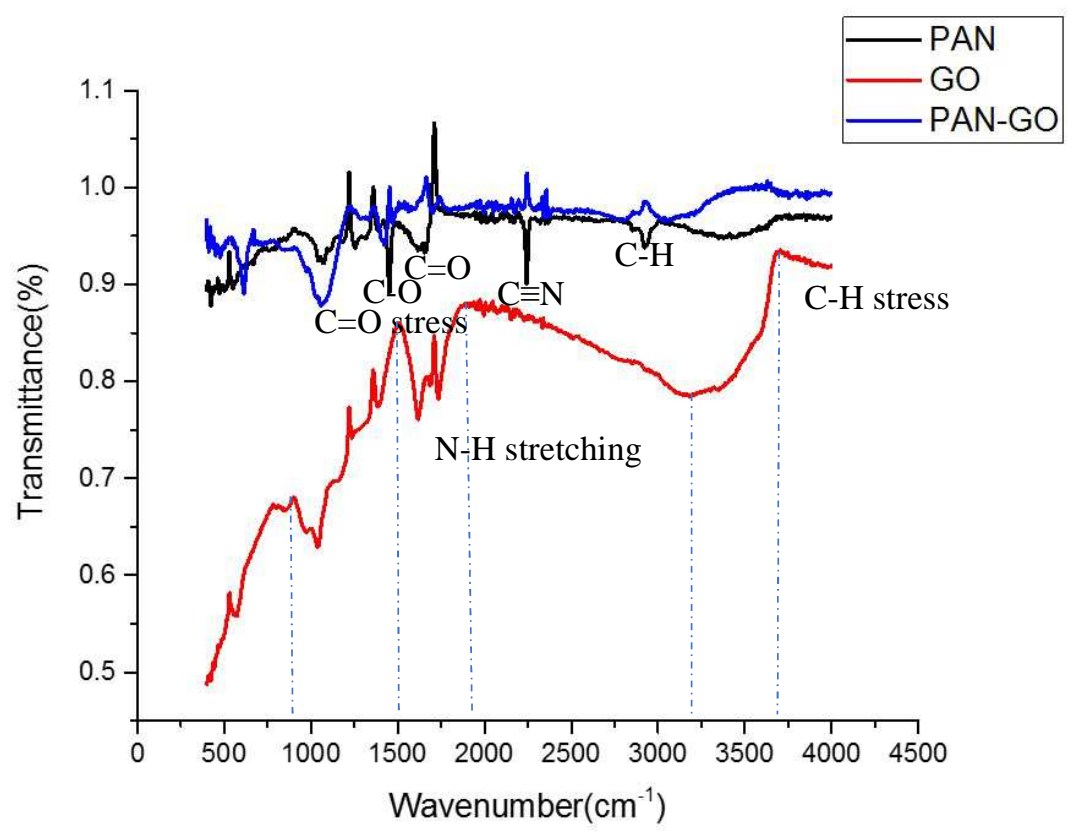

Figure 7 FTIR of GO, PAN and GO-PAN

The FTIR spectrum of PAN displays characteristic bands of methyl and methylene $\mathrm{C}-\mathrm{H}$ stretching vibrations at $3000 \mathrm{~cm}^{-1}$ and $1560 \mathrm{~cm}^{-1}$ respectively, as well as a strong band due to carbonyl groups at $1500 \mathrm{~cm}^{-1}(\mathrm{C}=\mathrm{O}$ stretch) and two bands due to ester linkages $(\mathrm{C}-\mathrm{O}-\mathrm{C}$ stretches). Therefore, it suggests there is good compatibility between GO and PAN. Another peak for PAN fibres is observed in the range of $2243-2246 \mathrm{~cm}^{-1}$ which is related to the presence of nitrile $(\mathrm{C} \equiv \mathrm{N})$ bonds, indicating that the nitrile group exists in the PAN chain. The broad signal between $3200 \mathrm{~cm}^{-1}$ and $3700 \mathrm{~cm}^{-1}$ is generated from $\mathrm{O}-\mathrm{H}$ stretching vibration and adsorbed water molecules. Two peaks at $2925 \mathrm{~cm}^{-1}$ and $2855 \mathrm{~cm}^{-1}$ are assigned to asymmetric and symmetric vibrations of $\mathrm{CH}_{2}$ groups, respectively. The strong signal at $1738 \mathrm{~cm}^{-1}$ in the GO's spectrum refers to the $\mathrm{C}=\mathrm{O}$ stretching vibration which was significantly weakened after reduction. The peak at $1622 \mathrm{~cm}^{-1}$ is attributed to the $\mathrm{C}=\mathrm{C}$ stretching vibration. There are carbonyl stretching regions $\left(1681-1764 \mathrm{~cm}^{-1}\right), \mathrm{CH}_{2}$ deformations (1380-1500 $\left.\mathrm{cm}^{-1}\right)$, and aromatic stretches from the hard segment $\left(1617 \mathrm{~cm}^{-1}\right)$, and amide II mixed band $\left(1540 \mathrm{~cm}^{-1}\right)$. 
Raman spectroscopy is widely used to characterise crystal structure, disorder and defects in graphene-based materials. Structural changes during the oxidation and reduction processes were monitored by Raman spectroscopy. Raman spectra of GO are characterised by the changes in the relative intensity of two main peaks: D and G. Raman scattering systems were also used to evaluate the hybridisation of the state in carbon, and the two reflection peaks change from pristine graphite to its derivatives. As shown in Figure 8a, a strong band at $1600 \mathrm{~cm}^{-1}$ (G band) and a relatively weak band at $1352 \mathrm{~cm}^{-1}$ (D band) appear in the Raman spectra of pristine graphite, which stem from the vibration of the $\mathrm{sp}^{2}$-hybridised graphitic domain, and $\mathrm{sp}^{3}$-hybridized carbon or structural defects, respectively. The low $\mathrm{I}_{\mathrm{D}} / \mathrm{I}_{\mathrm{G}}$ value (0.20) indicates the graphitic domains is primarily intact for pristine graphite. It was mainly induced by the n-type effect on the GO which forms the $\mathrm{sp}^{2}$ carbon modification to $\mathrm{sp}^{3}$ which is why the intensity ratio of $\mathrm{D}$ band and $\mathrm{G}$ bands decreased. Comparing the Raman spectra before and after pyrolysis (see Section 3.2), it has been revealed that there has been a clear change of crystal structure from pristine GO to GO-composite, indicating the reduction of GO into graphene (reduced graphene). The reduction of functional groups onto the surface of GO was also verified by the decrease in intensity of GO after pyrolysis (Figure $\mathbf{8 b}$ ).

It was observed in Figure $\mathbf{8 b}$ that there is a broad Raman peak centred at $1552 \mathrm{~cm}^{-1}$. The broadness of the Raman band suggests that PAN fibres represent disordered arrangements of PAN molecules. The sharpness of this peak was observed with increasing concentration of GO in the composite revealing the ordered arrangement of GO within composites. Two characteristic peaks at 1340 and $1552 \mathrm{~cm}^{-1}$ were observed in composites. These peaks correspond to the $\mathrm{D}$ and $\mathrm{G}$ bands from the defect structure of $\mathrm{sp}^{3}$-carbon and the plane vibration of the $\mathrm{sp}^{2}$-carbon atoms in a two-dimensional lattice of the GO-PAN composite ${ }^{36,37}$. 
Raman spectral signatures confirm that the cyclization of PAN is associated with graphitization. This feature was observed in all the spun fibres (Figure 8).
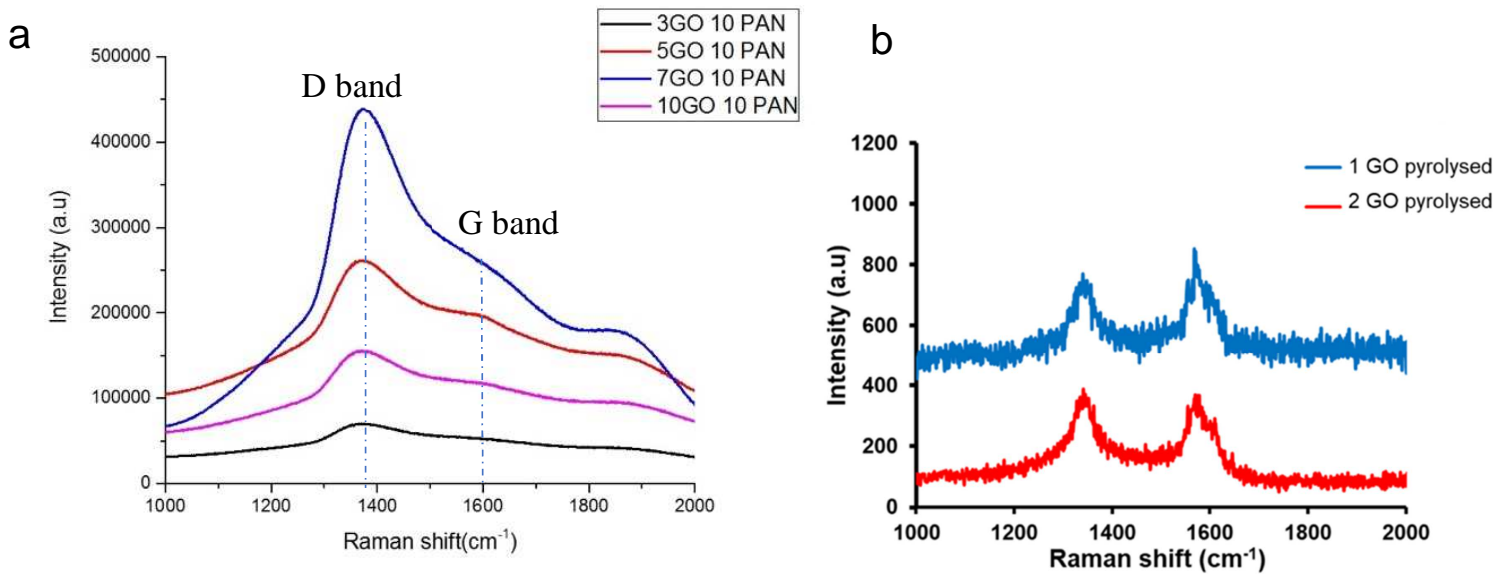

Figure 8 Raman spectroscopy of (a) as spun GO PAN solutions and (b) pyrolysed $10 \mathrm{GO} 1$ and 2 wt\% PAN

\subsection{Pyrolysed fibres}

To achieve optimal graphene fibre properties, a heating rate of $1{ }^{\circ} \mathrm{C} / \mathrm{min}$ and a treatment time of 30 min was used. After carbonization to $900{ }^{\circ} \mathrm{C}$, graphene fibres were obtained. A PANbased precursor containing carboxylic acid groups and acrylamide units was used for increasing the stabilization rate and sulphate/sulfonic groups for controlling the denseness of the precursor fibres ${ }^{38}$. Residues from the spinning solution can also behave as an initiator for nucleophilic cyclization reactions to reduce stabilization time ${ }^{39}$.

The fibre diameter was reduced with the removal of the non-carbon elements. At the early stages of carbonization, crosslinking reactions take place in the oxidized PAN. The cyclized structure starts to link up in the lateral direction by dehydration and denitrogenation. A planar structure can be formed with the basal planes oriented along the fibre axis. 
By increasing GO, the surface of the fibres became rougher and up to $3 \mathrm{wt} \%$ GO (Figure S2d), the fibres started to break. This supports the observation on electrical conductivity where only up to $2 \mathrm{wt} \%$ was significant. This might be due to the graphene fibres becoming brittle due to a high percentage of carbon caused by including PAN as a carbon precursor, which forms carbon during pyrolysis.

These fibres are generally called "high strength" fibres ${ }^{39}$. The strength of carbon fibre is observed to increase with the carbonization temperature and the maximum strength is observed at around $1500{ }^{\circ} \mathrm{C}$. Too fast carbonization introduces defects in carbon fibres, while a low carbonization rate causes the loss of too much nitrogen at the early stages of carbonization $^{39}$.

a
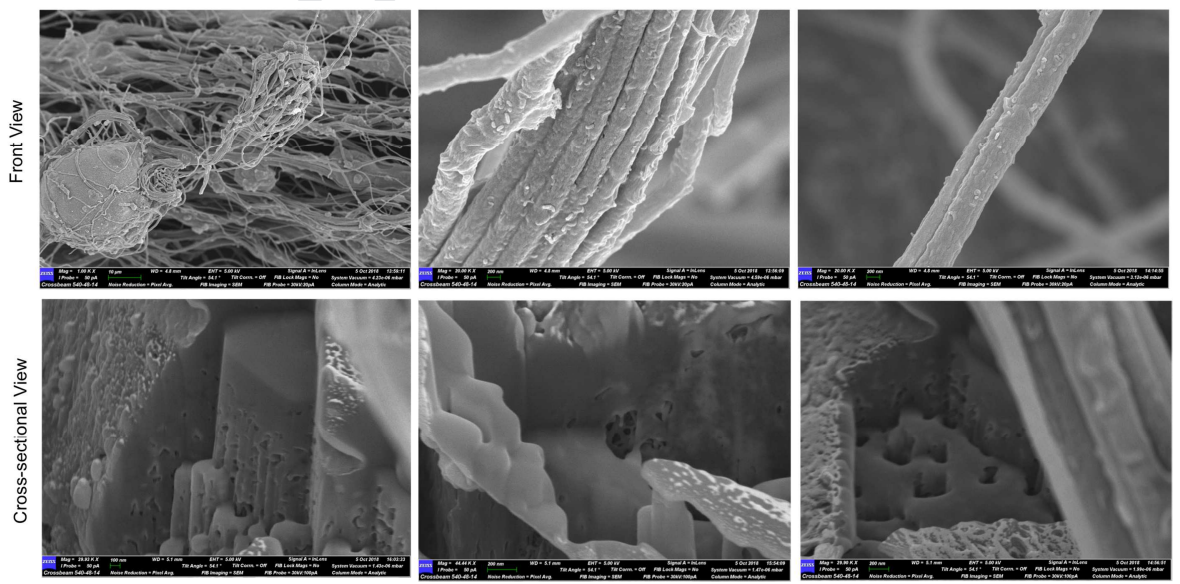


\section{Journal Pre-proof}

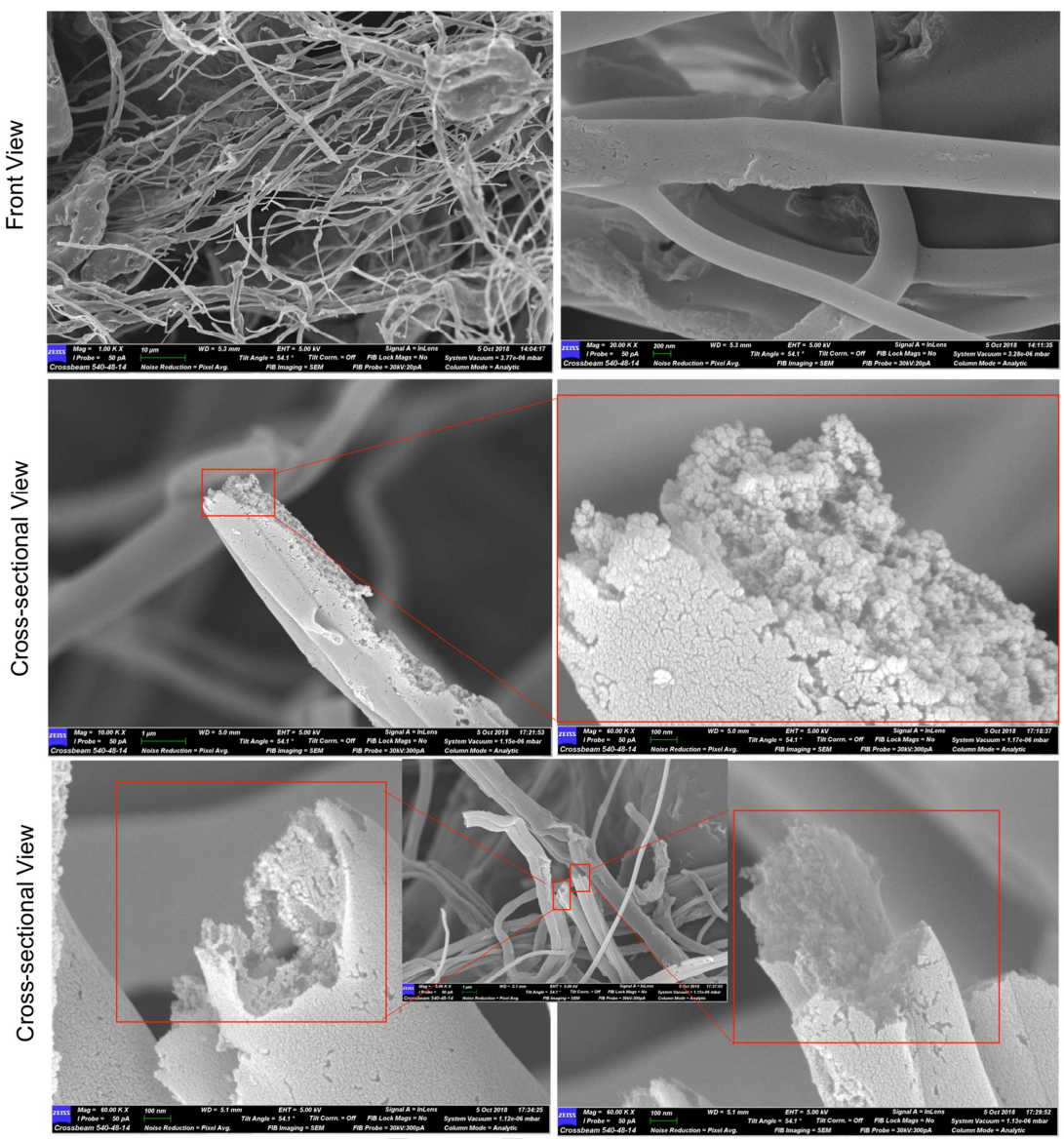

Figure 9. Scanning electron micrographs of focussed ion beam etched samples (a) control (b) prepared fibres

To verify the presence of graphene in the pyrolysed fibres, focussed ion beam cross-section studies were carried out (Figure 9). For the control sample, 10\% PAN fibres (without GO) were pyrolysed. Before SEM and FIB, a $15 \mathrm{~nm}$ coating of platinum (45s of sputtering was deposited). Pyrolysed 3wt\% GO - 10wt\% PAN fibres (Figure 9) show distinct grainy internal morphology, whereas the control (Figure 9a), pyrolysed 10wt\% PAN fibres show a smooth, porous internal structure.

\subsection{Electrical conductivity}

Figure 10 shows that a LED illuminates when connected to pyrolyzed fibres. However, only $1 \mathrm{wt} \%$ GO $10 \mathrm{wt} \%$ PAN and $2 \mathrm{wt} \%$ GO $10 \mathrm{wt} \%$ PAN with values of $973 \mathrm{~S} / \mathrm{m}$ and $459 \mathrm{~S} / \mathrm{m}$ 
respectively shared this phenomenon. There was no electrical conductivity in the as-spun fibres as the insulating behaviour of GO dominates. Even post-pyrolysis, at high percentages of GO, there is no conductivity because it became dependent on geometrical aspects like sheet orientation and percolation effects in the fibre, causing the gross diversity ${ }^{40}$. This situation complicates any prediction of the conductivities for GO composite material formulations and affects the reliability of any theoretical model or simulation ${ }^{41}$. Guex et. $\mathrm{al}^{40}$ suggested this was caused by the preferential attack of reducing agent on $\mathrm{C}-\mathrm{O}$ rather than $\mathrm{C}=\mathrm{O}$ groups. This is confirmed by the fact that the $\mathrm{G}$ band stronger at $1 \mathrm{wt} \% \mathrm{GO}$ than $2 \mathrm{wt} \%$ GO (Figure 8).
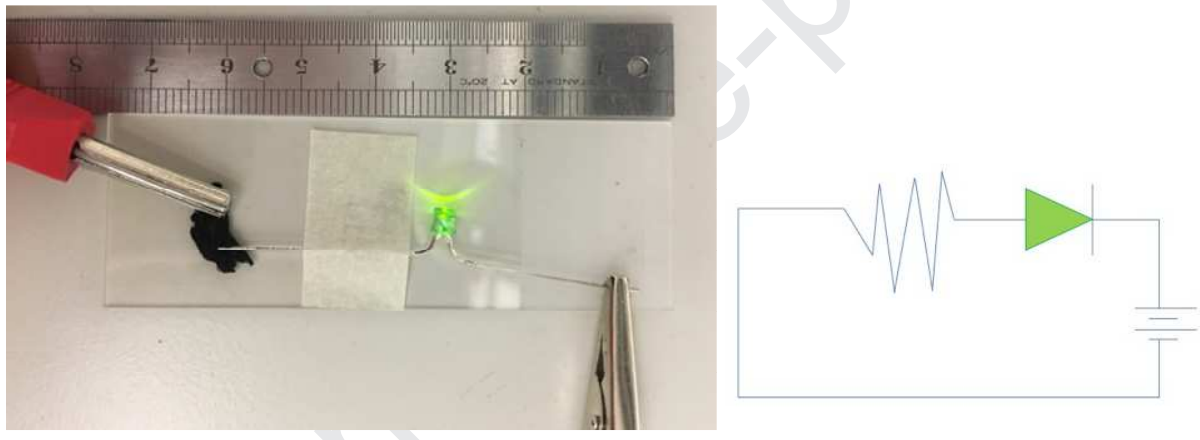

Figure 10 Electrical testing, inset shows the circuitry

\subsection{Conclusions}

Different GO-PAN compositions were processed using pressurised gyration to obtain fibrous products. The processing parameters such as rotating speed, working pressure and the concentration of GO-polymer composite solution had a significant influence the fibres formed. Generally lower concentration of GO and the higher rotating speed of $36 \mathrm{k} \mathrm{rpm}$ resulted in small fibre diameter. The fine fibres were also obtained by increasing the working pressure from $0.1 \mathrm{MPa}$ to $0.3 \mathrm{MPa}$. The fibre diameter distribution was unimodal for all the processing conditions and the mean diameter ranged from 1-20 $\mu \mathrm{m}$. The SEM and FIB 
imaging showed that GO platelets were incorporated in the fibres. The findings also revealed that fibre morphology was dependent on GO concentration. It was shown at $10 \mathrm{wt} \%$ PAN compared to lower concentrations of $8 \mathrm{wt} \%$, generated more fibres even at lower pressure and speed. Pyrolysed fibres showed granular morphology while the controlled sample without GO had a smooth surface. FTIR and Raman spectroscopy showed the characteristics of bonding existed in the polymer and GO. Fibres were successfully pyrolyzed, however, only lower loading of GO with $10 \mathrm{wt} \%$ PAN (1 - $2 \mathrm{wt} \%)$, had conductivity.

\section{Acknowledgement}

We thank Dr C.J. Luo, from the University College London for helping with the FIB-SEM images of this work.

\section{References}

1. Papageorgiou DG, Kinloch IA, Young RJ. Hybrid multifunctional graphene/glass-fibre polypropylene composites. Compos Sci Technol. 2016;137:44-51. doi:10.1016/j.compscitech.2016.10.018

2. Meng F, Wang M, Lu W, Li Q, Chou T-W, Zheng L. An electromechanical behavior of reduced graphene oxide fiber. Carbon $N \quad Y$. 2016;105:244-247. doi:10.1016/J.CARBON.2016.04.037

3. Huang G, Hou C, Shao Y, et al. Highly Strong and Elastic Graphene Fibres Prepared from Universal Graphene Oxide Precursors. Sci Rep. 2014;4:19812-19823. doi:10.1038/srep04248

4. Kim H, Jalili R, Spinks GM, Wallace GG, Kim SJ. High-strength graphene and polyacrylonitrile composite fiber enhanced by surface coating with polydopamine. Compos Sci Technol. 2017;149:280-285. doi:10.1016/J.COMPSCITECH.2017.05.029

5. Pathak AK, Borah M, Gupta A, Yokozeki T, Dhakate SR. Improved mechanical properties of carbon fiber/graphene oxide-epoxy hybrid composites. Compos Sci Technol. 2016;135:28-38. doi:10.1016/J.COMPSCITECH.2016.09.007

6. Salim NV, Jin X, Razal J. Polyacrylonitrile/liquid crystalline graphene oxide composite fibers - Towards high performance carbon fiber precursors. Compos Sci Technol. 2019;182:107781. doi:10.1016/J.COMPSCITECH.2019.107781

7. $\quad$ Pei S, Cheng H-M. The reduction of graphene oxide. Carbon $N$ Y. 2012;50(9):32103228. doi:10.1016/j.carbon.2011.11.010 
8. Park KE, Kim BS, Kim MH, You HK, Lee J, Park WH. Basic fibroblast growth factorencapsulated PCL nano/microfibrous composite scaffolds for bone regeneration. Polymer (Guildf). 2015;76:8-16. doi:10.1016/j.polymer.2015.08.024

9. Fan T, Zhao C, Xiao Z, et al. Fabricating of high-performance functional graphene fibers for micro-capacitive energy storage. Sci Rep. 2016;6(1):29534. doi:10.1038/srep29534

10. Hua C, Shang Y, Li X, et al. Helical graphene oxide fibers as a stretchable sensor and an electrocapillary sucker. Nanoscale. 2016;8(20):10659-10668. doi:10.1039/C6NR02111E

11. Meng F, Wang M, Lu W, Li Q, Chou T-W, Zheng L. An electromechanical behavior of reduced graphene oxide fiber. Carbon $N$ Y. 2016;105:244-247. doi:10.1016/J.CARBON.2016.04.037

12. Zheng X, Yao L, Mei X, Yu S, Zhang W, Qiu Y. Comparing effects of thermal annealing and chemical reduction treatments on properties of wet-spun graphene fibers. J Mater Sci. 2016;51(21):9889-9901. doi:10.1007/s10853-016-0222-z

13. Chen $\mathrm{Y}, \mathrm{Xu} \mathrm{J}$, Yang $\mathrm{Y}$, et al. PEDOT:PSS/graphene/PEDOT ternary film for high performance electrochemical electrode. $J$ Mater Sci Mater Electron. 2015;26(11):8292-8300. doi:10.1007/s10854-015-3494-1

14. Kou L, Huang T, Zheng B, et al. Coaxial wet-spun yarn supercapacitors for highenergy density and safe wearable electronics. Nat Commun. 2014;5(1):3754. doi:10.1038/ncomms4754

15. Xu Z, Gao C. Graphene chiral liquid crystals and macroscopic assembled fibres. Nat Commun. 2011;2:571. doi:10.1038/ncomms1583

16. $\mathrm{Hu} \mathrm{Y,} \mathrm{Cheng} \mathrm{H}$, Zhao F, et al. All-in-one graphene fiber supercapacitor. Nanoscale. 2014;6(12):6448. doi:10.1039/c4nr01220h

17. Ucar N, Gokceli G, Yuksek IO, Onen A, Karatepe Yavuz N. Graphene oxide and graphene fiber produced by different nozzle size, feed rate and reduction time with vitamin C. J Ind Text. 2018;48(1):292-303. doi:10.1177/1528083716685903

18. Uçar N, Ölmez M, Kayaoğlu BK, Önen A, Karatepe Yavuz N, Eksik O. Structural properties of graphene oxide fibers: from graphene oxide dispersion until continuous graphene oxide fiber. $J$ Text Inst. March 2018:1-11. doi:10.1080/00405000.2018.1454088

19. Tian Z, Xu C, Li J, Zhu G, Shi Z, Lin Y. Self-Assembled Free-Standing Graphene Oxide Fibers. ACS Appl Mater Interfaces. 2013;5(4):1489-1493. doi:10.1021/am303010j 
20. Liu Z, Xu Z, Hu X, Gao C. Lyotropic Liquid Crystal of Polyacrylonitrile-Grafted Graphene Oxide and Its Assembled Continuous Strong Nacre-Mimetic Fibers. Macromolecules. 2013;46(17):6931-6941. doi:10.1021/ma400681v

21. Liu Y, Xu Z, Zhan J, Li P, Gao C. Superb Electrically Conductive Graphene Fibers via Doping Strategy. Adv Mater. 2016;28(36):7941-7947. doi:10.1002/adma.201602444

22. Amir A, Mahalingam S, Wu X, et al. Graphene nanoplatelets loaded polyurethane and phenolic resin fibres by combination of pressure and gyration. Compos Sci Technol. 2016;129:173-182. doi:10.1016/j.compscitech.2016.03.031

23. Wu X, Mahalingam S, Amir A, Porwal H. Preparation and characterisation of PANbased carbon nanofibres with GNPs using pressurised gyration and spark plasma sintering. ACS Omega. 2016;1(2):202-211.

24. Chong WG, Xiao F, Yao S, et al. Nitrogen-doped graphene fiber webs for multibattery energy storage. Nanoscale. 2019;11(13):6334-6342. doi:10.1039/C8NR10025J

25. Eigler S. Graphite sulphate - a precursor to graphene. Chem Commun (Camb). 2015;51(15):3162-3165. doi:10.1039/c4cc09381j

26. Rahaman MSA, Ismail AF, Mustafa A. A review of heat treatment on polyacrylonitrile fiber. Polym Degrad Stab. 2007;92(8):1421-1432. doi:10.1016/j.polymdegradstab.2007.03.023

27. Chung DDL. Continuous carbon fiber polymer-matrix composites and their joints, studied by electrical measurements. Polym Compos. 2001;22(2):250-270. doi:10.1002/pc.10536

28. Mahalingam S, Edirisinghe M. Forming of polymer nanofibers by a pressurised gyration process. Macromol Rapid Commun. 2013;34(14):1134-1139. doi:10.1002/marc.201300339

29. Mahalingam S, Pierin G, Colombo P, Edirisinghe M. Facile one-pot formation of ceramic fibres from preceramic polymers by pressurised gyration. Ceram Int. 2015;41(4):6067-6073. doi:10.1016/j.ceramint.2015.01.065

30. Marcano DC, Kosynkin D V, Berlin JM, et al. Improved synthesis of graphene oxide. ACS Nano. 2010;4(8):4806-4814. doi:10.1021/nn1006368

31. Kralchevsky PA, Nagayama K. Capillary interactions between particles bound to interfaces, liquid films and biomembranes. Adv Colloid Interface Sci. 2000;85(23):145-192. doi:10.1016/s0001-8686(99)00016-0

32. Alenezi H, Emin Cam M, Edirisinghe M. Experimental and theoretical investigation of the fluid behavior during polymeric fiber formation with and without pressure. Appl Phys Rev. 2019;6:41401. doi:10.1063/1.5110965 
33. Park S, Ruoff RS. Chemical methods for the production of graphenes. Nat Nanotechnol. 2009;4(4):217-224. doi:10.1038/nnano.2009.58

34. Dong Z, Jiang C, Cheng $\mathrm{H}$, et al. Facile Fabrication of Light, Flexible and Multifunctional Graphene Fibers. Adv Mater. 2012;24(14):1856-1861. doi:10.1002/adma.201200170

35. Oh JY, Park J, Jeong YC, Kim JH, Yang SJ, Park CR. Secondary Interactions of Graphene Oxide on Liquid Crystal Formation and Stability. Part Part Syst Charact. 2017;34(9):1600383. doi:10.1002/ppsc.201600383

36. Tabish T, Pranjol M, Horsell D, et al. Graphene Oxide-Based Targeting of Extracellular Cathepsin D and Cathepsin L As A Novel Anti-Metastatic Enzyme Cancer Therapy. Cancers (Basel). 2019;11(3):319. doi:10.3390/cancers11030319

37. Hassan FM, Batmaz R, Li J, et al. Evidence of covalent synergy in silicon-sulfurgraphene yielding highly efficient and long-life lithium-ion batteries. Nat Commun. 2015;6(1):8597. doi:10.1038/ncomms9597

38. Park SJ, Heo GY. Precursors and manufacturing of carbon fibers. Springer Ser Mater Sci. 2015;210:31-66. doi:10.1007/978-94-017-9478-7_2

39. Huang X. Fabrication and Properties of Carbon Fibers. Materials (Basel). 2009;2(4):2369-2403. doi:10.3390/ma2042369

40. Guex LG, Sacchi B, Peuvot KF, et al. Experimental review: chemical reduction of graphene oxide (GO) to reduced graphene oxide (rGO) by aqueous chemistry. Nanoscale. 2017;9. doi:10.1039/c7nr02943h

41. Yoonessi M, Gaier JR. Highly Conductive Multifunctional Graphene Polycarbonate Nanocomposites. ACS Nano. 2010;4(12):7211-7220. doi:10.1021/nn1019626 


\section{Declaration of interests}

\The authors declare that they have no known competing financial interests or personal relationships that could have appeared to influence the work reported in this paper.

$\square$ The authors declare the following financial interests/personal relationships which may be considered as potential competing interests: 